\title{
INTENT, PSYCHOSOCIAL CORRELATES AND PSYCHIATRIC DIAGNOSIS OF PATIENTS WHO ATTEMPTED SUICIDE
}

\author{
Pallab Kumar Bhattacharjee', Manju P. Baruah²
}

${ }^{1}$ Assistant Professor, Department of Psychiatry, Jorhat Medical College, Jorhat.

${ }^{2}$ Psychiatric Social Worker, Department of Psychiatry, Jorhat Medical College, Jorhat.

\begin{abstract}
BACKGROUND

Psychosocial correlates reveal that majority of patients who attempted suicide had mild level of stress and they belonged to a problematic family. The most common psychiatric diagnosis was found to be Adjustment disorder followed by Depressive disorder. The aim of this study is to assess the intent, psychosocial correlates and psychiatric diagnosis of patients who attempted suicide.
\end{abstract}

\section{MATERIALS AND METHODS}

This was a descriptive study conducted at Outpatient Department, Department of Psychiatry, Jorhat Medical College and Hospital.

\section{RESULTS}

Majority of the subjects had stressors that prompted them to make this decision to commit suicide. $84.8 \%$ of patients belong to problematic family and $24.2 \%$ of patients have moderate level of stress.

\section{CONCLUSION}

Suicide is a complex behaviour that needs appropriated theoretical models for prevention.

\section{KEYWORDS}

Psychosocial Intent, Psychosocial Factors, Psychiatric Diagnosis, Patients Who Attempted Suicide.

HOW TO CITE THIS ARTICLE: Bhattacharjee PK, Baruah MP. Intent, psychosocial correlates and psychiatric diagnosis of patients who attempted suicide. J. Evolution Med. Dent. Sci. 2017;6(70):5013-5016, DOI: 10.14260/Jemds/2017/1089

\section{BACKGROUND}

Suicides have occurred since the beginning of recorded history. Suicide is viewed as a way out of a problem or crisis that is invariably causing intense suffering. According to Edwin Shneidman, suicide is associated with unfilled needs, feelings of hopelessness and helplessness, ambivalent conflicts between survival and unbearable stress, narrowing of perceived options and a need for escape; the suicidal person sends out signals of distress. In the year 2000, approximately one million people died from suicide; global mortality rate of 16 per 100,000 , or one death every 40 seconds. In the last 45 years, suicide rates have increased by $60 \%$ worldwide. Suicide is now among the three leading causes of death among those aged 15-44 years; these figures do not include suicide attempts. Suicide rates have been highest among the male elderly, rates among young people have been increasing to such an extent that they are now the group at highest risk in a third of countries, in both developed and developing countries. Mental disorders particularly depression and substance abuse are associated with more than $90 \%$ of all cases of suicide. However, suicide results from many complex sociocultural factors and is more likely to occur particularly during periods of socioeconomic, family and individual crisis situation.

Financial or Other, Competing Interest: None.

Submission 04-05-2017, Peer Review 20-08-2017,

Acceptance 26-08-2017, Published 31-08-2017.

Corresponding Author:

Manju P. Baruah,

Bosco Institute,

Life Plus, Jorhat

E-mail: manjupbaruah@gmail.com

DOI: $10.14260 /$ jemds/2017/1089
Several groups of youths are at high risk of suicide attempts: gay, lesbian, and bisexual youth, those who are homeless, runaways and delinquents, those who have incarcerated, and those who have been exposed to suicidal behaviour of others (Friends, family members, etc.). Suicide among youths, which is one of the biggest social issues that is never talked about openly and discussed about due to its association with stigma and its associated things like name and fame, dignity and status of the family. Even though people understand that it is a social problem, they are afraid of discussing about it even among much educated people. It is more alarming to hear that most youths of today are more prone of attempting suicide. Throughout early adolescence suicidal behaviour is relatively uncommon among males, with female attempters outnumbering males, usually in the order of 5:1. Among the youths increasing numbers of young men are becoming more vulnerable to suicidal behaviour.

Suicide is often associated and carried out as a result of despair, the cause of which is frequently attributed to a mental disorder such as depression, bipolar disorder, schizophrenia, borderline personality disorder, and alcoholism or drug abuse. Stress factors such as financial difficulties or troubles with interpersonal relationships can cause a person to commit suicide. Besides there are a number of reasons and the related causes as to why the rate of attempting suicide among young people is growing every day. At several times, youths have the feelings of hopelessness, worthlessness and loneliness and they feel lost. These feelings among the youths compel them to attempt suicide. The feeling of loneliness, hopelessness and worthlessness are caused by other factors like burden because of divorced parents, abuse in childhood, loss of dear ones, etc. 
Suicide which most people thought it as a crime and sin was never thought that it was the problem of the society and not as serious issue among people. Suicide even though it is considered as socially not acceptable and prohibited, there were no enough efforts put in to prevent people from attempting it. Though it can be prevented it was never taken seriously for preventing it before it really happened. People who are in danger of harming themselves may try out with another person directly or indirectly sometimes. This reaction can happen to someone with whom the victim has established a professional relationship or to a person whom the victim sees for the first time.

Most people who attempted suicide do not absolutely want to die but it is the reaction to crises in their lives that are standing unsolved. Therefore, the need to identify the problems and solving them becomes important. The rise of suicide rates sought for the need of more preventive measures, and for sensitisation.

Suicide is a major cause of mortality and it is also a serious public health problem all over the world.1,2 Young people show increasing trend in attempted suicide than other groups in developed and developing countries. Exams, peer pressure and emotional issues are the factors that led to suicide attempts. ${ }^{3,4}$

According to most of the literatures, it was found that for several years the suicide rate has been rising very rapidly among the young people, particularly, males 15 to 29 years old. In the 15-29 years old male age group, suicide is just behind accidents and homicides as a cause of death. Over the last 50 years, the number of suicides among teenagers has shot up, and it has tripled since 1970. Throughout early adolescence suicidal behaviour is relatively uncommon among males, with female attempters outnumbering males, usually in the order of 5:1. However, some studies suggest that increasing numbers of young men are becoming more vulnerable to suicidal behaviour. Males are vulnerable to suicides and more prone to using deadly means with less chances of recovery like firearms, hanging, jumping from buildings or running in front of speedy vehicles.

According to the National Crime Records Bureau (NCRB), 2012, the major causes of suicides in India are family problems and illness accounting for $25.6 \%$ and $20.8 \%$ respectively. Drug abuse or addiction, love affairs, bankruptcy, sudden change in economic status, dowry dispute accounting for $3.3 \%, 3.2 \%, 2 \%, 1.9 \%$ and $1.6 \%$ respectively were the other causes of suicidal deaths in India. Suicides due to drug abuse or addiction has shown an increased percentage rate, whereas fall in social reputation, failure in examination, property dispute have shown a decreasing percentage during last three years. However, suicidal deaths due to bankruptcy or sudden changes in economic status, cancellation or non-settlement of marriage, suspected or illicit reactions, divorce, bareness or impotency, dowry dispute, family problems, illegitimate pregnancy, love affairs, professional or career problem, unemployment and poverty show mixed percentage rate during this period.

The suicide rates are on the rise in India, especially in southern part of the country. The southern states of India namely Tamil Nadu, Andhra Pradesh, Karnataka, and Kerala have a higher suicide rate than the northern states. It is estimated that half million people die of suicide every year worldwide, among which $20 \%$ are Indians.

In the year 2006, 526 people committed suicide. In the year 2007, it had decreased to 483 in India as according to the Ministry of Health. Suicide kills more people each year than conflicts and natural death, accounting for more than half of the world's 1.5 million as accounted according to results of research done by World Health Organization. Studies also found that the most common methods of committing suicide globally were pesticide poisoning, hanging and firearms.

In a study conducted to know the cause of suicide reveals that family poverty, school failure, alcohol and drug use, and depression probably cause suicide. Gay, lesbian and bisexual youths also are at high risk for suicide, making attempts at the rate this time higher than other adolescents. Those who have tried to kill themselves report more family conflicts, inner turmoil about the sexuality, problems in romantic relationships and peer rejection due to their sexual orientation. ${ }^{5}$

Stress and anxiety can have serious consequences for one's well-being. Stress and anxiety can lead to eating disorders, substance abuse, mood swings, forgetfulness, decreased immunity, sleep problems, high blood pressure, heart problems and social issues such as withdrawal and conflict with loved ones. Stress and anxiety have been linked with generalised anxiety disorders and depression. ${ }^{6}$

Risk factors of suicide may include mental disorders such as depression, personal disorder, alcohol dependence or schizophrenia or some physical health problems. Suicide ranks as the $10^{\text {th }}$ leading cause of death in the world. Globally an estimated of 700,000 people take their own lives annually and suicide accounted for 12 deaths for every 100,000 people nationwide; making it the $10^{\text {th }}$ leading cause of death. ${ }^{7}$

American Association of Suicidology states the connection between depression and suicide. Major depression is the mental health disorder most often connected to suicide. About $66 \%$ of those who committed suicide are struggling with depression at the time they take their lives, those with drug or any substance abuse or addiction issues who are diagnosed with depression are at greater risk of suicide. As many as two thirds of people with depression do not realise that they have a treatable illness and do not seek treatment. Only $50 \%$ of persons diagnosed with major depression receive any kind of treatment, and only $20 \%$ of those individuals receive treatment consistent with current practice guidelines as according to the American Psychiatric Association (APA). More alarming, in a large Canadian study, $48 \%$ of patients who had suicidal ideation and $24 \%$ of those who had made a suicide attempt reported not receiving care or even perceiving the need for care.

Depression is actually a complex of feelings that can include helplessness, low self-esteem, and even an inner sense of deserving whatever bad things happen as defined by Abramson, Seligman and Teasdale, 1978. Depression is also known as clinical depression. Depression can manifest a large variety of symptoms, most often feeling of despair or sadness that does not go away. The factors that can cause depression are loss of job, divorce, loss of loved one, etc.

When struggling with depression, many patients turn to alcohol, heroin, prescription drugs and other substances in an effort to fill the emptiness and escape the pain that comes 
with untreated depression. Unfortunately, drug use only serves to increases the symptoms associated with depression, lengthen depression episodes, and create a host of physical and social problems along the way. One of the many problems faced by those who attempt to self-treat their depression through drugs and alcohol is a high risk for suicide.

\section{MATERIALS AND METHODS}

This was a descriptive study conducted at Outpatient Department, Department of Psychiatry, Jorhat Medical College and Hospital which is a 500-bedded medical college hospital catering to the health requirements of the people of Jorhat District. Present study got research ethical committee clearance from Jorhat Medical College \& Hospital.

\section{Inclusion Criteria}

All attempted suicide patients admitted in the Medical wards during the period of $1^{\text {st }}$ April 2015 to $1^{\text {st }}$ April 2016, age group 15-40, male and female, married and unmarried included in this study.

\section{Exclusion Criteria}

The patients who died during the recovery phase from physical ill health following attempted suicide were excluded from the study.

\section{Procedure}

The present study included 33 cases of attempted suicide patients who were admitted in the medical wards or ICU. After admission, patients were treated in the wards or in the ICU and referred to the consultant psychiatrists for evaluation after the physical condition was stabilised.

Psychiatric assessment was done by consultant psychiatrist and a psychiatric diagnosis according to the ICD10. Data was collected for the present study based on the notes made by the consultant and Psychiatric case records. To assess the intent of suicide, Beck's suicide intent scale was used and to assess psychosocial correlates Perceived stress scale was applied to know the level of stress and Family Assessment Device - General Functioning Scale was used to know the general function of the respondent's family.

\section{Statistical Analysis}

For the analysis of the data, the researcher used statistical package of social sciences. Descriptive data presented as mean and range values. Multiple group comparisons were done by Chi square test. For all the tests, the probability value (p-value) of less than 0.05 was considered statistically significant.

\section{RESULTS}

a) Sociodemographic Variables of the Study SampleDuring the one year study period 33 patients were admitted in the medical wards for treatment of attempted suicide which shows that majority (52\%) of respondents belongs to 18-23 years age group (44.3\%), majority $(45.5 \%)$ of people had Secondary education. $54.5 \%$ patients were unmarried. Majority of patients (87.9\%) belonged to Hindu religion. $81.8 \%$ of patients belonged to Assamese community. Majority (48.5\%) belonged to semi-urban background. Majority are from Joint family than nuclear family. Majority are from low middle socioeconomic status.

\section{b) Suicide Intent}

Majority of the patients who attempted suicide had low and medium intent to commit suicide, which is $45.5 \%$. The remaining patients had high intent of committing suicide, which is $9.1 \%$. Therefore, present study reveals that, patients who attempted suicide did not have high intent to commit suicide.

c) Psychiatric Diagnosis in Patients who Attempted Suicide

33 patients admitted during the study period and received services from Psychiatry, it reveals that majority of the subjects had stressors that prompted them to make this decision to commit suicide. Majority of patients had a psychiatric diagnosis except a few. Major of subjects had psychiatric diagnosis of Adjustment disorder (60.6\%), Depression (30.3\%) and 9.1\% were diagnosed with schizophrenia.

d) Psychosocial Correlates of Patients who Attempted Suicide

To know the psychosocial correlates, the level of stress and family function of the patients were assessed which reveals-

- Perceived stress of patients who attempted suicideMajority (60.6\%) of patients who attempted suicide had mild stress. $24.2 \%$ patients had severe stress followed by moderate level of stress which is $15.2 \%$.

- Family function of patients who attempted suicideMajority of patients' families (84.8\%) were problematic families and $15.2 \%$ were nonproblematic.

e) Psychosocial Problems and Intent of Suicide

Stress and family functioning are taken as psychosocial factors in this study. Chi-square test result 0.007 reveals that there is association between intent of suicide and level of stress. Chi-square result of 0.006 reveals that there is association between intent of suicide and family function.

The result reveals there is an association between intent of suicide and psychosocial problems.

f) Education and Intent of Suicide

Patients who had secondary education had low suicide intent. Chi-square test result 0.82 reveals that there is no association between education and intent of suicide.

g) Psychiatric Diagnosis and Intent of Suicide

Patients who had adjustment disorder had low intent of suicide. Chi-square test result 0.01 reveals that there is association between psychiatric diagnosis and intent of suicide among studied population.

\section{DISCUSSION}

Suicide attempt can be defined as a non-fatal, self-directed potentially injurious behaviour with intent to die. ${ }^{8}$ In India, the number of suicides during 2002-2012 has recorded an increase of $22.7 \% .{ }^{9}$ Attempted suicides are 20 times more common than completed suicide (WHO, 2012). People those who engage in non-fatal suicidal behaviours, one-third repeat the behaviour within a year and nearly $10 \%$ eventually commit suicide. ${ }^{10,11,12}$

According to stress-vulnerability model, suicidal behaviour occurs when there is imbalance between risk factors and protective factors. In this study, patients who 
attempted suicide did not have high intent to commit suicide. However, psychiatric diagnosis, personal conflicts and lack of support were found to be the main reason for suicide attempts. Suicide attempts usually occurred after physical or psychological abuse such as blame or scolding by the patient's significant one. This kind of phenomenon is highlighted by World Health Organization's strategies of how to prevent domestic violence and avoid battering of children and partners.

Research suggests that psychiatric illness constitutes a major cause for non-fatal suicidal behaviour. Risk for nonfatal suicide attempts by adults or youth include depression and other mental disorders. $13,14,15$

Research done in the area of Suicide and psychiatric diagnosis reveals that mood disorders (Depression and Mania), schizophrenia, substance-related disorders and personality disorders were the common psychiatric diagnosis made for people who committed suicide. ${ }^{16}$

There is usually prolonged distress associated with psychiatric disorder, physical illnesses, personality disturbances and stress factors. In this study, diagnoses reveal that majority of patients had psychiatric diagnoses except a few. Major subjects had psychiatric diagnosis of Adjustment disorder (60.6\%) followed by Depression (30.3\%) and 9.1\% were diagnosed with schizophrenia.

Suicide attempt is a complex behaviour which does not occur due to a single social or psychological reason. There are many protective factors such as problem-solving capacity, asking for help from friends, family, professionals and good relationships with the family and others where reducing stress is important to overcome situation. Poor relationship and inappropriate coping strategies lead to suicide attempt in times of distress. Present study reveals that Majority of patients who attempted suicide had mild stress (60.6\%), $24.2 \%$ patients had severe stress followed by moderate level of stress which is $15.2 \%$ and family function of patients who attempted suicide reveals that majority of patients' families $(84.8 \%)$ were problematic families and only $15.2 \%$ were nonproblematic.

\section{CONCLUSION}

In this study, majority of patients who attempted suicide had secondary education. Collaboration, coordination, cooperation and commitment are needed from the professionals to prevent suicide and save lives. Health professionals can play an effective role in preventing and rehabilitating persons with suicidal tendencies. There is a need for more 'crisis intervention centres' In India to get immediate help.

\section{REFERENCES}

[1] WHO. The World Health Report 1999.

[2] Ninerenberg AA, Gray SM, Grandin LD, et al. Mood disorders and suicide. Journal of Clinical Psychiatry 2001;62(Suppl 25):254-67.

[3] Shamsi Y, Ahmad J, Khan AA. A clinical study on the management of anxiety neurosis with Sankhaholi. Indian Journal of Traditional Knowledge 2007;6(4):668-77.

[4] The World Health Report. Geneva, 1995: p. 17.

[5] Maris RW. Suicide. Lancet 2003;360(9329):319-26.

[6] Eddleston M, Sheriff R, Hawton K. Deliberate self harm in Sri Lanka: an overlooked tragedy in the developing world. British Medical Journal 1998;317(7151):133-5.

[7] Krug EG, Dahlberg LL, Murcy JA. World report on violence and health. Geneva, World Health Organization 2002.

[8] Accidental deaths and suicide in India. National Crime Records Bureau. Ministry of Home Affairs. 2012. Last accessed on 2014 Sep 18. http://ncrb.nic.in/CD-ADSI 2012/ADSIHome2012.htm.

[9] World Health Organization (WHO), Suicide prevention, 2012. Last accessed on 2014 Sep 18. http://www.who.int/mental_health/prevention/suici de/suicideprevent/en/index.html.

[10] Pirkis J, Beautrais A, Durkee T. Suicide attempts in New Zealand and Australia. In: Wasserman D, Wasserman C. eds. Oxford textbook of suicidology and suicide prevention: a global perspective. Oxford: Oxford University Press 2009:127-31.

[11] Silverman M. Suicide attempts in North America. In: Wasserman D, Wasserman C. eds. Oxford textbook of suicidology and suicide prevention: a global perspective. Oxford: Oxford University Press 2009: 117-21.

[12] Kessler RC, Borges G, Walters EE. Prevalence of and risk factors for lifetime suicide attempts in the National Comorbidity Survey. Arch Gen Psychiatry 1999;56(7):617-26.

[13] Chang B, Gitlin D, Patel R. The depressed patient and suicidal patient in the emergency department: Evidence-based management and treatment strategies. Emerg Med Pract 2011;13(9):1-23, 24.

[14] Bertolote JM, Fleischmann A, De Leo D, et al. Psychiatric diagnoses and suicide: revisiting the evidence. Crisis 2004;25(4):147-55.

[15] Bertolote JM, Fleischmann A. Suicide and psychiatric diagnosis: a worldwide perspective. World Psychiatry 2002;1(3):181-5.

[16] http://www.who.int/mental_health/prevention/suici de/suicideprevent/en/ 